\title{
Social Aspects of the Quality of Life of Persons Suffering from Schizophrenia
}

\author{
Gitte Lee Mortensen ${ }^{1}$, Jayanti De², Mads Holme², Tina Neve3, Per Göran Torell4, \\ Jonas Eberhard ${ }^{5,6}$ \\ ${ }^{1}$ Anthro Consult, Aarhus, Denmark \\ ${ }^{2}$ ReD Associates, Copenhagen, Denmark \\ ${ }^{3}$ Project CHANGE, Capital Region Psychiatry, Copenhagen, Denmark \\ ${ }^{4}$ European Federation of Associations of Families of People with Mental IIIness (EUFAMI), Leuven, Belgium \\ ${ }^{5}$ Department of Clinical Sciences, Lund University, Lund, Sweden \\ ${ }^{6}$ Institute of Psychiatry, Psychology \& Neuroscience (IoPPN), King's College, London, UK \\ Email: *glm@anthroconsult.d
}

Received 20 October 2015; accepted 26 December 2015; published 29 December 2015

Copyright (C) 2016 by authors and Scientific Research Publishing Inc.

This work is licensed under the Creative Commons Attribution International License (CC BY).

http://creativecommons.org/licenses/by/4.0/

C) (i) Open Access

\section{Abstract}

Background: Several studies have shown that persons with schizophrenia (PWS) suffer from severely reduced quality of life (QoL). Impaired social functioning is a defining characteristic of schizophrenia (SZ) and social cognition deficits affect interpersonal relations and outcomes such as independent living, vocational functioning and employment status. Some studies have demonstrated important socio-cultural aspects of SZ, for instance by examining experiences of SZ in different developing countries and among minority groups in the Western world. The socio-cultural context is central to understanding patients' experiences in any society, however. Using an anthropological approach, we use qualitative research methods to examine patient perspectives on SZ. Sampling and Methods: In-depth qualitative interviews are carried out with SZ patients in France, the UK and the USA representing diversity in Western mental health systems. Results: To the participants, the most important QoL aspects are close relations and support from loved ones, a safe home and comfort zone, and meaningful daily activities. Normalisation and independence act as central themes to patients' QoL and hopes for social integration. The participants need a buffer zone consisting of social relations, a home and daily occupation that is flexible and may balance issues of equality/inequality, abnormality/normality, and dependence/independence. Conclusion: By using participatory methods, PWS may be involved in shaping their own treatment and recovery plans based on what is subjectively meaningful and beneficial to their mental health. QoL and functioning are closely linked to the socio-cultural context in which health care structures go hand in hand with health care cultures that shape patients' expectations and preferences.

*Corresponding author.

How to cite this paper: Mortensen, G.L., De, J., Holme, M., Neve, T., Torell, P.G. and Eberhard, J. (2016) Social Aspects of the Quality of Life of Persons Suffering from Schizophrenia. Open Journal of Psychiatry, 6, 50-60.

http://dx.doi.org/10.4236/ojpsych.2016.61005 
Recovery is thus related to the possibilities and challenges posed by the socio- cultural context.

\section{Keywords}

Schizophrenia, Quality of Life, Socio-Cultural Aspects, Patient Perspectives, Qualitative Research

\section{Introduction}

Schizophrenia (SZ) is a mental disorder with a lifetime prevalence of approximately 1\% [1] [2]. The symptoms are often grouped into two clusters: "positive symptoms", i.e. features added to the normal state such as hallucinations and delusions; and "negative symptoms", i.e. the absence of features normally present such as blunting of affect, poverty of speech, and lack of motivation. Symptoms often referred to as "general" include affective, motor and cognitive symptoms [3] [4]. Negative symptoms and cognitive impairments have been shown to most significantly impacting patients' daily coping abilities, but they are difficult to treat [5]. The long term outcomes are influenced by treatment type and intensity, with relapses fuelling the progression of the illness [6].

Several studies have shown that persons suffering from SZ (PWS) experience much reduce health-related quality of life (QoL) [1] [7]-[10]. Impaired social functioning is a defining characteristic of SZ often implying deterioration of interpersonal relations, social rejection, withdrawal and stigma [11]-[13]. Social functioning deficits are linked to impaired neuro-cognitive skills including memory, attention and executive functions that impact functional outcomes such as independent living, vocational functioning and employment status [8] [14]. According to some, many deficits of SZ are a result of poor metacognition, i.e. the ability to reflect upon the mental states of one self and others and to use this knowledge in social interactions and problem solving [15]. Social cognition deficits thus have major impact on social integration and QoL [8] [16] [17]. Within psychiatry, there is a recognized need for psychosocial interventions of which a number have been developed such as social skills training and cognitive behavioural training (CBT) [18]-[21].

The assessment of the psychosocial QoL and functioning of PWS has mainly used quantitative tools [22] [23]. Some original studies have shed light on important socio-cultural aspects of SZ examining the relations between SZ and gender or age or experiences with SZ in different socio-cultural settings [24]-[27]. Others have suggested social explanatory causes for SZ such as minority status, urban dwelling, social exclusion, and socioeconomic status [28] [29]. Studies of SZ across cultural contexts have shown differences in symptoms and presentations as well as outcomes and prognoses [25] [30].

From the perspective of medical anthropology, the socio-cultural context should be a key analytical framework for examining patient experiences in any society. Every society enshrines cultural values around family and community, gender and age, with dominant cultural perceptions of SZ bearing upon social integration and exclusion. Also, national health care structures are closely linked to informal health care cultures defining how treatment is financed and who is perceived to be responsible for psychiatric care. It is our objective to use qualitative research methods to gain an in-depth understanding of the QoL of PWS in their socio-cultural contexts.

The present study followed up on a cross-national study that examined the experiences of SZ of PWS, their caregivers and psychiatric health care professionals (HCP) with the aim to identify unmet disease management and treatment needs. This initial study was carried out by ReD Associates, Copenhagen, Denmark. Qualitative interviews were carried out in France, USA and the UK to represent diversity in mental health care systems. The USA had great state-level variation in care with California, New York and Pennsylvania representing mixed service provisions with Medicare/Medicaid, private insurance and out-of-pocket payments. The US had seen a nationwide de-institutionalization but many states suffered from shortages of community mental health services [31]. A number of self-help networks provided services for housing and health management. The UK represented a deinstitutionalized, community care system with various teams providing care and support to PWS [32]. This primarily included Community Mental Health Teams, but also Crisis Resolution Teams and Early Intervention Teams. In the UK, a number of NGOs and publicly funded health services such as Mind and Rethink were organized in local networks that included supported housing, crisis helplines, drop-in centres, and employment and training schemes. France was selected due to its dominant public hospital care model that was 
mixed with community care. Approximately 50\% of French PWS received out-patient care while 50\% were partially or fully hospitalized. Public care included local Centres Médicale Psychiatriques (CMP) offering semiannual consultations with a psychiatrist as well as daily supported activities; and Hôpitaux de Jours (Day Hospitals). With the general lack of social housing in France, living with the family was common for many PWS [33] [34]. Following up on this initial study, the present study applied a medical anthropological approach to further explore the patients' experiences with SZ in their differing socio-cultural environments.

\section{Methods}

\subsection{The Initial Research Project: Unmet Needs in the Management of Schizophrenia}

For the initial study, nine psychiatric HCPs from France, the UK and the USA were included of which boardcertified psychiatrists identified eligible PWS. At scheduled controls, the psychiatrist informed eligible patients and their caregiver(s) about the study, both orally and in writing. A maximum variation sampling procedure was adopted to enable diversity across a number of socio-demographic and medical variables including time since SZ diagnosis, gender, type of treatment and housing situation. All PWS were stable at the time of interviews (Table 1).

Across the three countries, 22 interviews were carried out with caregivers with nine PWS participating. One PWS was interviewed alone. Interviews were carried out by native French or English speaking social science researchers from ReD Associates. Caregivers and PWS were assured that their anonymity would be safeguarded and that they might opt-out at any time. All interviewees provided written consent to participate. The study met the ethical standards outlined by the ICC/ESOMAR International Code of Social Research and EphMRA. Following the preferences of the participating PWS, most interviews took place at caregivers' or PWS' residencestwo were carried out in meeting rooms at SHARE (the Self-Help and Recovery Exchange), Los Angeles. The interviews were carried out as informal, open-ended inquiries with minimal prompts to enable the participants to take the lead in their narratives and elaborate on areas most important to them. The interview guide covered four main areas of exploration: 1) Onset of schizophrenia: from childhood to key life events, initial perceptions of symptoms and diagnosis; 2) Treatment journey, perceived efficacy of treatments, acute crises, and experiences with the care systems; 3) Caregivers' experiences and; 4) Living with schizophrenia: everyday challenges, coping and management as well as aspirations of PWS and caregivers. To help trigger memories and provide visual overviews of the participants' perspectives, the interviews included three written exercises: a schizophrenia development timeline (1); a patient journey timeline (2) and care coordination map (3) [35]. These exercises were carried out with the assistance of the researchers when needed. All interviews were videotaped and selectively transcribed into interpretive field-note documentation. The interviews lasted four to six hours but varied with regard to how long the PWS participated (1 - 2 hours). This generated a vast amount of data that was analysed using a multi-tiered grounded theory approach [36]. Five main unmet needs commonly faced by PWS and/or caregivers and/or HCPs were identified: 1) Minimizing the impact of side effects of pharmaceutical treatment; 2) Provision of targeted and personalised medicine; 3) Provision of more convenient treatment dosing and administration; 4) Support for caregivers and; 5) Improving knowledge and understanding about SZ in society.

\subsection{The Present Follow-Up Study: Focusing on the Patient Perspective}

A specialized medical anthropologist, GLM, was subsequently brought on to conduct an in-depth qualitative analysis of the interviews with PWS aiming to produce a more focused analysis of the patient perspective: How did the PWS describe the QoL impact of SZ and their needs with regard to improving their health-related QoL?

GLM carried out a systematic literature search of journal articles published 2003-2014. Embase, Medline and PsycInfo were searched using the terms: "schizophrenia" combined with "quality of life", "social aspect/factor/ functioning”, "stigma/stereotype” or "psychosocial” (applying mesh, exact, and explode strategies). This search yielded 1543 articles of which 110 were selected for analysis. GLM studied all reports produced by ReD Associates and excluded interviews with HCPs and caregivers alone. The interviews carried out with caregivers and PWS together $(n=9)$ or PWS alone $(n=1)$ were then re-analysed (Table 1$)$. This involved transcribing verbatim the sections where PWS were present.

GLM analysed the patient interviews using a discourse theoretical approach implying that participants' 
Table 1. Participant characteristics of patients with schizophrenia.

\begin{tabular}{|c|c|c|c|c|c|c|c|}
\hline PWS & Gender & $\begin{array}{l}\text { Years } \\
\text { of age }\end{array}$ & $\begin{array}{l}\text { Years } \\
\text { since } \mathrm{dx}^{*}\end{array}$ & Residence & $\begin{array}{l}\text { Experience } \\
\text { with work } \\
\text { since } d x\end{array}$ & $\begin{array}{l}\text { Current (near) } \\
\text { daily occupation }\end{array}$ & Treatment \\
\hline A & F & 49 & 20 & $\begin{array}{l}\text { Lyon, France } \\
\text { Ownapt. }\end{array}$ & $\begin{array}{l}\text { Protected } \\
\text { Work }\end{array}$ & CMP & $\mathrm{AP}$ \\
\hline B & F & 38 & 10 & $\begin{array}{l}\text { Lyon, France } \\
\text { with spouse }\end{array}$ & - & $\begin{array}{l}\text { Day hospital } \\
\text { and CMP }\end{array}$ & $\begin{array}{c}\text { AP Scheduled admissions } \\
\text { to hospital every six } \\
\text { weeks for } 1 \text { - } 2 \text { weeks } \\
\text { Weekly consultations } \\
\text { with nurse at the CMP }\end{array}$ \\
\hline C & $\mathrm{M}$ & 59 & 30 & $\begin{array}{l}\text { Paris Suburb, } \\
\text { France } \\
\text { with Sister }\end{array}$ & $\begin{array}{l}\text { Protected } \\
\text { Work }\end{array}$ & $\begin{array}{c}\text { None } \\
\text { Recently } \\
\text { declared inapt } \\
\text { for work }\end{array}$ & $\begin{array}{c}\text { AP } \\
\text { Psychotherapy } \\
\text { Previously: CBT } \\
\text { (privately), }\end{array}$ \\
\hline D & M & 27 & $7-8$ & $\begin{array}{l}\text { Village near } \\
\text { Lyon, France } \\
\text { with Parents }\end{array}$ & $\begin{array}{l}\text { Employed } \\
\text { at fathers' } \\
\text { company }\end{array}$ & CMP & $\begin{array}{c}\text { AP } \\
\text { CBT at the CMP }\end{array}$ \\
\hline E & M & 43 & 10 & $\begin{array}{l}\text { London, UK } \\
\text { Ownappt. }\end{array}$ & - & None & $\begin{array}{c}\text { AP } \\
\text { CPN every three weeks }\end{array}$ \\
\hline $\mathrm{F}$ & M & 25 & 5 & $\begin{array}{l}\text { Birmingham, UK } \\
\text { with Parents and } \\
\text { Sister }\end{array}$ & - & $\begin{array}{l}\text { None/self-study } \\
\text { of website } \\
\text { production }\end{array}$ & $\begin{array}{c}\text { AP } \\
\text { CPN every } 2^{\text {nd }} \text { week } \\
\text { Previously: CBT and EIT }\end{array}$ \\
\hline G & $\mathrm{F}$ & 41 & 12 & $\begin{array}{c}\text { New York City, } \\
\text { USA } \\
\text { Independent } \\
\text { Living House } \\
\text { on/off Homeless }\end{array}$ & - & $\begin{array}{l}\text { On/off medical } \\
\text { day centre with } \\
\text { various activities }\end{array}$ & $\begin{array}{c}\text { On/off AP } \\
\text { On/off peer support groups } \\
\text { Alternative care facilities } \\
\text { (not specified) } \\
\text { Frequent hospital } \\
\text { admissions }\end{array}$ \\
\hline $\mathrm{H}$ & $\mathrm{F}$ & 54 & $20+$ & $\begin{array}{c}\text { Los Angeles, } \\
\text { USA } \\
\text { Own Appt. }\end{array}$ & $\begin{array}{l}\text { Various temp } \\
\text { and project jobs }\end{array}$ & $\begin{array}{c}\text { Attends and } \\
\text { volunteers at } \\
\text { peer-to-peer } \\
\text { groups (SHARE) }\end{array}$ & $\begin{array}{c}\text { AP } \\
\text { Self-help/peer support } \\
\text { groups } \\
\text { Psychiatrist (private) }\end{array}$ \\
\hline I & $\mathrm{F}$ & 74 & $40+$ & $\begin{array}{l}\text { Los Angeles, } \\
\text { USA } \\
\text { with Spouse }\end{array}$ & $\begin{array}{l}\text { Ordinary } \\
\text { employment } \\
\text { (real estate) }\end{array}$ & $\begin{array}{l}\text { Retired from } \\
\text { work Active in } \\
\text { Recovery } \\
\text { International }\end{array}$ & $\begin{array}{l}\text { No medication } \\
\text { Self-help/peer support in } \\
\text { Recovery International }\end{array}$ \\
\hline $\mathrm{J}$ & M & 38 & 3 & $\begin{array}{l}\text { Los Angeles, } \\
\text { USA } \\
\text { Independent } \\
\text { living Facility/ } \\
\text { Collaborative } \\
\text { Housing }\end{array}$ & - & $\begin{array}{c}\text { Attends } \\
\text { peer-to-peer } \\
\text { groups (SHARE, } \\
\text { AA, NA, Our } \\
\text { Way) GED } \\
\text { course }\end{array}$ & $\begin{array}{c}\text { AP } \\
\text { Self-help/various } \\
\text { peer support groups } \\
\text { GP, psychiatrist, therapist, } \\
\text { care worker }\end{array}$ \\
\hline
\end{tabular}

*Abbreviations: Dx: diagnosis; AP: Anti-psychotic medicine; CMP: Centre medico-psychologique; CBT: Cognitive behavioural training; EIT: Early intervention team; CNP: Community psychiatric nurse; GED: General educational development; GP: General practitioner.

statements were seen as an ongoing interpretation of the impact of having SZ. This approach is a means to analyse a variety of statements so that clusters of meaning can be generated. It involves an analysis of the terminology used to speak about the subject and the ways in which it is related to other issues. Firstly, the data was coded into the topics raised by the PWS. Secondly, the most important themes within each topic were identified. Finally, the frequency of and connections between topics and themes were analysed. This generated a pattern of the relative meaning that the different topics and themes held the PWS, i.e. their own most significant experiences with SZ [37]. All methodological and analytical steps were discussed among the authors, including the impact of interviewer/interviewee interaction [38]. 


\section{Results}

\subsection{The Importance of Close Interpersonal Relations}

Most participants found their main support within their immediate family, primarily their mother and secondarily, one or more sisters. Other family members had often withdrawn from the PWS. For the three participants having a partner, these had become main caregivers providing emotional and practical support. Caregivers helped the participants with remembering their medication, having regular meals, keeping up appointments, and coordinating their care with health care professionals (HCP). Close relatives had usually played a crucial role in initially pushing for care and were still helping to maintain good routines and to navigate the health care system particularly when concerning benefits, housing, protected jobs or day facilities. As one 43 year-old British PWS put it, "mum helps bring everything together". Parents had or were still providing PWS with a place to live, and in the USA, some gave financial support for housing or treatment. In two cases, parents had adopted children of female patients. Many participants simultaneously needed, appreciated and resented the dependence upon their relatives. At some point, most wanted to become more independent, to live by themselves and be more in charge of their own care and life. Increased independence allowed for more equal relations and a feeling of capability and self-esteem.

To the three (female) participants having found a partner, this was the main source of their QoL. Having somebody to love and share their life with was crucial. One 38 year-old French woman said her husband was the one to "blow life into her", "to bring reality in", and without whom, she would be very alone.

Five participants had no friends. One was disappointed that her old friends had not been able to cope with her disease. Two participants had a few old friends. Only two (US) female patients stated to have several friends. Still, friends were mostly described as people not fully knowing about or understanding the disease: "I find it hard to talk about it to any of my friends, because they wouldn't understand. You just get labelled as mad, you know" (43 year-old British man).

\subsection{The Importance of Meaningful Occupation: Work, Day Centres and Peer Support Groups}

Today, none of the participants worked. Two were retired, three were too sick, and some were currently unable to find suitable jobs. Still, those who had previously had protected or ordinary jobs felt this had heightened their self-esteem and integration in society. For most of those not having worked since their diagnosis, getting training or work was a major future goal. One UK participant said that work was a main part of his identity: "I want to better myself. I want to go back to work, because I was always a worker. I need to do the computer course to gain the confidence" (43 year-old man). When the issue of work came up during the interviews, all PWS participated eagerly: "I worked at the DSRP [a production enterprise for the mentally disabled] and even if we weren't paid... it was still work, you know!" (49 year-old French woman). It was, however, important to some that the job involved interaction with "normal people”. In France, work places must employ 5\% disabled people. This had previously allowed one 58-year-old male participant to get various temporary positions. When he was recently declared inapt to work, this was a major blow to his self-esteem and feeling of being part of society. He explained that while working, he got out of the house every day and managed transportation on his own. Since stopping, he stayed in and felt increasingly insecure and anxious about his ability to cope with the outside world. It had, in other words, diminished his confidence and his comfort zone immensely.

Three French patients attended day centres for the mentally ill participating in hiking trips, art and writing classes, or music therapy. Some said that going to the Centre Médicale Psychiatrique (CMP) was an important means to having a daily routine and to getting out of the house. The CMP prevented social isolation and anxiety and could augment a sense of pride in achieving new skills. In France, the CMP thus acted as a means to train and uphold social functioning. In the UK, two participants rejected group activities for the mentally ill due to social phobia, insecurity and a wish to be around "normal people".

In the USA, three PWS were involved in peer support groups such as those organised by SHARE. These groups were crucial to their QoL with respect to managing different aspects of their disease, achieving new skills and significantly enhancing their self-esteem by way of helping others. For instance, one PWS found support in groups dealing with alcohol and substance abuse; others had attended groups dealing with stigma management and hoarding. One woman said that "At first, I was a zombie. Then little by little, I could produce post- 
ers... Today, I tutor others" (54 year-old woman). The participants described peer groups as a means to organise their own care, impede negative disease developments as well as provide a central social scene to meet, share and get the feeling that others cared.

Patient quote 1. Social disease management through peer support.

"In this therapy, there is a structure, and it's a bit stricter. You have to work. You have to practice and listen to your peers as they help you pick up on behaviour that might be toxic to your mental health... They are not just saying: here, take your medication and come and see me in three months, but here are some activities and some things to bolster you. Come here if you are feeling down and they will give you support, looking at the whole life of the person" (74 year-old woman speaking of Recovery International).

\subsection{The Importance of Home}

The participants had various residential situations (Table 1). Overall, the private home was described as a sign of capability and functioning; an achievement to some, a key goal to others. Some described having a private home as a precondition to remission. One 38 year-old French participant considered her home as a "cocoon" where she could hide with her husband and their dogs, a safe place vis-à-vis the complicated outside world. A suitable alternative the parents' home was sometimes difficult to find, however. In the UK, supported housing is only a temporary housing solution. In France, the participants considered the so-called "appartementsthérapeutiques" almost impossible to get. In the US, organisations such as SHARE may provide collaborative housing. To some PWS, supported housing was the first step towards independence: "Moving out of my mum's house made me my own independent self. I started opening up to the outside world" (38 year-old American man). Others found it difficult to cohabit with other mentally ill persons due to problems arising from social phobia, OCD, drug abuse or troubling sexual encounters with co-residents.

All three participants living by themselves stayed in close proximity to their parents. One considered her apartment a place to withdraw to when she was "getting on her family's nerves" (49 year-old French woman). The cousin of a British participant said that the mother had created a "controlled environment" for her son who could always come around and felt safe in the familiar neighbourhood. This PWS said that he was proud of "managing on his own and have his 'private space among normal people" (43 year-old man).

Patient quote 2. The private home is integral to recovery.

"If it wasn't for the MH [the UK Mental Health service], I wouldn't have had my own flat close to my mum who is my carer. I see her every day. We have a good relationship. I have something with trust. I don't trust people, only my mum and my cousin, Joe. I find it hard to get close to people. It's the trust, you know"... "Much as I come around here [at his mother's place] every day and we have dinner together, I love my own space. She's my carer but I like to go home every night and sleep in my own bed. It's very important to me. Since I got that flat, it's like I have started over, but everything in it, I got from others. If I save up, I can make it better, do it up and buy new furniture, and that will make me feel better.... The MH supported me in every way, they found me a flat and they made me well" (43 year-old man).

\subsection{Stigma and Empowerment}

Coping with the stigma around SZ was a significant part of most participants' disease journeys: "I spent most of my life trying to be comfortable and open about my mental illness. I always tell myself I am the happiest and healthiest I've ever been. Why should I feel ashamed?" (74 year-old American woman). Some were affected by misconceptions of SZ and PWS as violent, dangerous people with a split personality. They stressed that SZ involves different symptoms for different people. Many participants suffered from low self-esteem, insecurity and social phobia. They felt different, unwanted or lacking in ordinary social skills. Due to stigma, some preferred concealing their disease from others. The unwillingness to be identified with the disease was one of the reasons 
that many preferred being around "normal people". As one UK participant said: "people don't understand it; only the close family... Sometimes, I feel you get a bit labelled like you are mad. Today, I'm a $100 \%$ better. I'm not mad, but if I stopped taking my medication and I would start hearing voices, I would probably do some mad things" (43 year-old man). This description implies a crucial distinction between identity and behaviour.

Nevertheless, most participants also showed various signs of empowerment. Those living by themselves were proud to manage on their own. Three US participants felt dignity in having sought help in peer support groups and participated actively in their own recovery. Also, most participants having lived with SZ for several years had arrived at a point where, should they be lacking medication, they could positively act upon this themselves. One 38 year-old French woman voluntarily admitted herself to hospital with regular intervals. Furthermore, some had identified activities that made them feel good, such as writing, doing improvisation theatre, or juggling and they had found ways to do this in comfortable surroundings.

Patient quote 3. Patients' capabilities to identify sources of mental health and well-being.

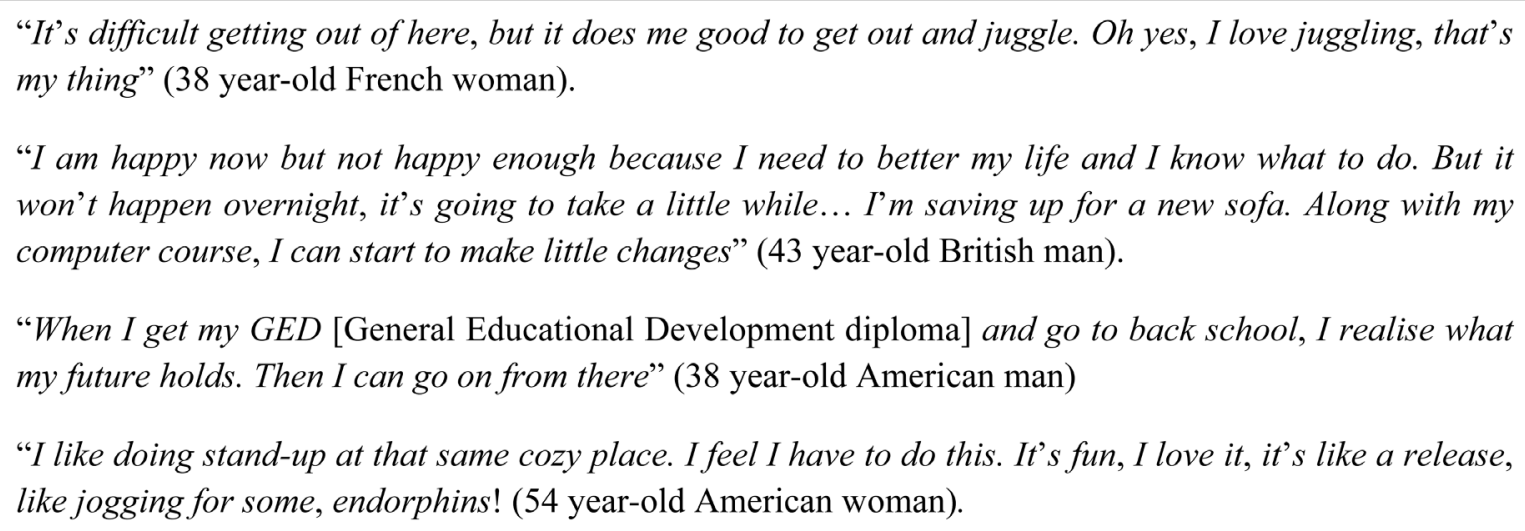

Most participants thus had clear ideas of what made them feel better and, just as importantly, dreams and hopes for the future.

\section{Discussion}

As depicted in Figure 1, the aspects of life perceived to be most meaningful to the participants were close relations and support from loved ones, a safe home environment and meaningful daily occupation—be it work, day centre activities or peer support groups. Normalisation and independence acted as central themes within all spheres, i.e. having equal relations, managing your own care and everyday life, as well as using your competences, acquiring skills or enjoying your hobbies within a more or less protected environment. The participants needed a sort of buffer zone consisting of relations, a home and daily occupation that was flexible and supportive and might balance the issues of equality/inequality, abnormality/normality, and dependence/independence (Figure 1).

The importance of interpersonal relations and employments had previously been described by others [8] [11], and clearly, the main QoL areas that we identified-having close relations, a home and meaningful daily occupations were not particular to PWS but pertained to most people. And here was indeed a central point as these QoL areas were ordinary things that people communicated about with others-hence their normalising function. To PWS, they served to connect naturally with others, as opposed to the social isolation created by impairment and stigma. Fulfilment of these areas might thus enhance social integration and familiarity with PWS in the community.

There was no one kind of home or occupation that fitted all needs. Instead, a personalised buffer zone should be based on individual needs. This echoes other studies finding that interventions should be tailored to patients' subjectively assessed QoL [7] [39]. As Lepageand colleagues pointed out, functioning was relevant in relation to individual goals, and as such, these should be the target of a broad treatment approach [14]. Our study indicated that by using participatory methods, PWS might be able to co-create their buffer zone. Following Becker and colleagues [40], mental health systems should thus not only empower patients to navigate in their care context but base their support on patients' pre-existing empowerment. Much as we needed to acknowledge the severe nega- 


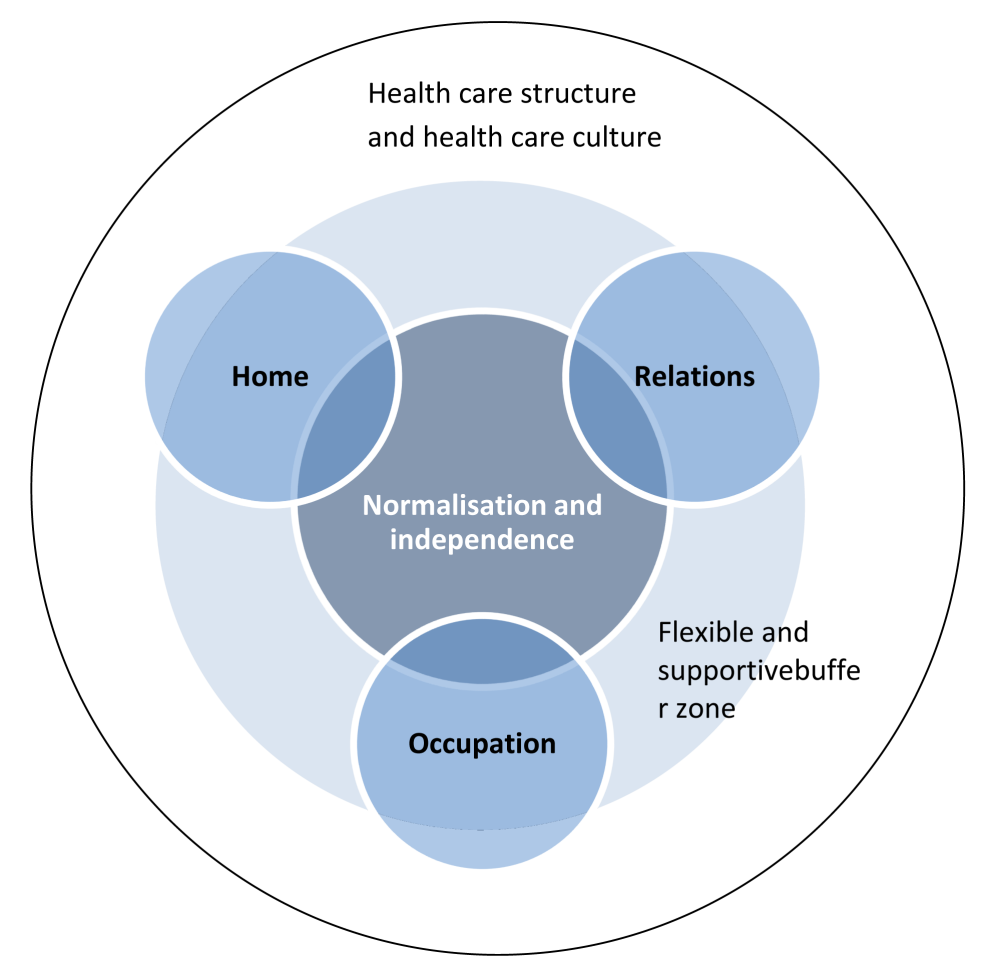

Figure 1. Quality of life of schizophrenia in context.

tive QoL impacts of SZ, it was crucial to also recognise the capacities that PWS might have to identify their own needs and hopes for the future.

It was a limitation with this study that our sample of participants across three countries was very small. In qualitative studies, the aim was to provide analytical rather than statistical generalisations [41]. However, as the preceding study had a broader aim-including caregiver and HCP perspectives, the data collection among patients did not continue until saturation point and the methodological design was less targeted. As such, our results should be interpreted with caution and further examinations of the patient perspective should be carried out in a larger sample of PWS. For instance, this might produce more in-depth knowledge about our and others' indications that female PWS had better social functioning than males with similar symptom profiles [11]. Furthermore, the presence of caregivers in our interviews allowed most PWS to feel comfortable about participating; it was also likely to have influenced the PWS' accounts, however. Finally, this study was likely to involve some selection bias as our participants were relatively stable, accepting of their SZ diagnosis, received some treatment and caregiver support. It was well known that many PWS struggled with lack of insight and adequate treatment, substance abuse or social issues such as homelessness implying very poor QoL and functioning [1] [42]. Finally, using an anthropological approach, the present study had emphasised social factors related to the QoL of PWS. While recognising the crucial impact of psychiatric variables (such as symptomology and neuro-cognition) and psychological variables to QoL (such as self-efficacy and coping), these factors had not been represented in this study [9].

Our study underlines previous findings that health related QoL and functioning are closely linked to the socio-cultural context [16] [25] [27] [43] [44]. The UK health care system is communitarian in its focus on supporting the individual in his or her home and local community. Rather than treatment having a strongly social aspect, however, it requires a tight local cooperation between various health care agents. The UK also has a strong workers culture implying that to many, work may be considered crucial to self-esteem and identity. Our UK participants were reluctant to participate in group activities targeted at the mentally ill, but might benefit from more opportunities of getting supported work in ordinary work places. By contrast, in the USA, self-help through peer support is a core value making treatment and recovery a highly social endeavour. To our participants, less emphasis was on the value of working and rather more on values of sharing, participating and con- 
tributing in group-oriented therapies. In the US, this is accompanied by a comparatively weak public support system that increases the importance of socio-economic status and volunteer networks. Finally, in France, the social aspect is also highly valued albeit in a different manner. Here, there is a strong public sector emphasising social integration of the mentally ill in work places, but also prioritises social activities at CMPs creating social spheres that are somewhat secluded from the outside world. Still, in France too, cutbacks imply that it may be difficult to gain access to mental health care benefits, of which supported housing appears to be a particularly unmet need.

Health care structures go hand in hand with health care cultures that shape patients' expectations and preferences. What is perceived as supportive relations, a desirable home and meaningful occupation is both subjectively and culturally defined. Each society has dominant values about who is responsible for caring for the ill, perceptions of mental illness, expected expressed emotions and normalisation techniques to socially include PWS [25] [27] [30]. As Myers pointed out, recovery is related to the challenges posed by the socio-cultural context, for example how cognitively demanding different housing or job facilities are. This is why we find divergent real-world outcomes in PWS with similar levels of ability and potential [25]. As suggested by Trujols, Kingston-Steven and colleagues [8] [39], we confirm that it is highly relevant to apply ethnographic analyses to cultural models of SZ in order to apply this in treatment, facilitate recovery and support PWS with the most contextually relevant care in any society.

\section{Acknowledgements}

The authors wish to thank all interview participants for taking their time to share their experiences as well as Randa Tawil, Gavyn Edmunds and Rebecca Helena Graversen from ReD Associates for carrying out the qualitative interviews with patients and caregivers.

\section{Funding}

This work was supported by H. Lundbeck A/S

\section{References}

[1] Millier, U.S., Angermeyer, M.C., Chauhan, D., Murthy, V., Toumi, M. and Cadi-Soussi, N. (2014) Humanistic Burden in Schizophrenia: A Literature Review. Journal of Psychiatric Research, 54, 85-93. http://dx.doi.org/10.1016/j.jpsychires.2014.03.021

[2] Saha, S., Chant, D., Welham, J. and McGrath, J. (2005) A Systematic Review of the Prevalence of Schizophrenia. PLoS Medicine, 2, e141. http://dx.doi.org/10.1371/journal.pmed.0020141

[3] American Psychiatric Association (2013) Diagnostic and Statistical Manual of Mental Disorders. 5th Edition (DSM-5), APA, Washington

[4] Hirsch, S.R. and Weinberger, D.R. (2003) Schizophrenia. Wiley-Blackwell, Oxford.

[5] Velligan, D.I. and Alphs, L.D. (2008) Negative Symptoms in Schizophrenia: The Importance of Identification and Treatment. Psychiatric Times, 25, 1-2.

[6] Emsley, R., Chiliza, B. and Asmal, L. (2013) The Evidence for Illness Progression after Relapse in Schizophrenia. Schizophr Res, 148, 117-121. http://dx.doi.org/10.1016/j.schres.2013.05.016

[7] Awad, A.G. and Voruganti, L.N.P. (2012) Measuring Quality of Life in Patients with Schizophrenia. An Update. Pharmacoeconomics, 30, 183-195. http://dx.doi.org/10.2165/11594470-000000000-00000

[8] Kingston Stevens, A., McNichol, J. and Magalhaes, L. (2009) Social Relationships in Schizophrenia: A Review. Personality and Mental Health, 3, 203-216. http://dx.doi.org/10.1002/pmh.82

[9] Yanos, P.T. and Moos, R.H. (2007) Determinants of Functioning and Well-Being among Individuals with Schizophrenia: An Integrated Model. Clinical Psychology Review, 27, 58-77. http://dx.doi.org/10.1016/j.cpr.2005.12.008

[10] Bobes, J., Paz Garcia-Portilla, M., Bascaran, M.T., Saiz, P.A., Bousoño, M., et al. (2007) Quality of Life in Schizophrenic Patients. Dialogues in Clinical Neurosciences, 9, 215-226.

[11] Hooley, J.M. (2010) Social Factors in Schizophrenia. Current Directions in Psychological Science, 19, $238-242$. http://dx.doi.org/10.1177/0963721410377597

[12] Birgenheir, D.G. and Pepper, C.M. (2013) Social Functioning across the Course of Schizophrenia. Current Psychiatry Reviews, 9, 284-292. http://dx.doi.org/10.2174/15734005113096660006 
[13] Burns, T. and Patrick, D. (2007) Social Functioning as an Outcome Measure in Schizophrenia Studies. Acta Psychiatrica Scandinavica, 116, 403-418. http://dx.doi.org/10.1111/j.1600-0447.2007.01108.x

[14] Lepage, M., Bodnar, M. and Bowie, C.R. (2014) Neurocognition: Clinical and Functional Outcomes in Schizophrenia. Canadian Journal of Psychiatry, 59, 5-12.

[15] Brüne, M., Dimaggio, G. and Lysaker, P.H. (2011) Metacognition and Social Functioning in Schizophrenia: Evidence, Mechanisms of Influence and Treatment Implications. Current Psychiatry Reviews, 7, 239-247. http://dx.doi.org/10.2174/157340011797183210

[16] Hoertnagl, C.M. and Hofer, A. (2014) Social Cognition in Serious Mental Illness. Current Opinion in Psychiatry, 27, 197-202. http://dx.doi.org/10.1097/YCO.0000000000000055

[17] Prouteau, A. and Doron, J. (2008) Prédicteurs cognitifs des différentes dimensions du fonctionnement dans la communauté dans la schizophrénie: revue de la literature et perspectives. L'Encéphale, 34, 360-368. http://dx.doi.org/10.1016/j.encep.2006.06.003

[18] Elis, O., Caponigro, J.M. and Kring, A.M. (2013) Psychosocial Treatments for Negative Symptoms in Schizophrenia: Current Practices and Future Directions. Clinical Psychology Review, 33, 914-928. http://dx.doi.org/10.1016/j.cpr.2013.07.001

[19] Brown, E.C., Tas, C. and Brüne, M. (2012) Potential Therapeutic Avenues to Tackle Social Cognition Problems in Schizophrenia. Expert Review of Neurotherapeutics, 12, 71-81. http://dx.doi.org/10.1586/ern.11.183

[20] Dixon, L.B., Dickerson, F., Bellack, A.S., Bennett, M., Dickinson, D., Goldberg, R.W., et al. (2010) The 2009 Schizophrenia PORT Psychosocial Treatment Recommendations and Summary Statements. Schizophrenia Bulletin, 36, 48-70. http://dx.doi.org/10.1093/schbul/sbp115

[21] Mueser, K.T., Deavers, F., Penn, D.L. and Cassisi, J.E. (2013) Psychosocial Treatments for Schizophrenia. Annual Review of Clinical Psychology, 9, 465-497. http://dx.doi.org/10.1146/annurev-clinpsy-050212-185620

[22] Price, M.A., Hill, C.D., Williams, V.S.L., Morlock, R.J., Leeuwenkamp, O. and Patterson, T.L. (2008) Measures of Functional Status and Quality-of-Life in Schizophrenia. Current Psychiatry Reviews, 4, 28-38. http://dx.doi.org/10.2174/157340008783743839

[23] Brissos, S., Molodynski, A., Videira Dias, V. and Figueira, M.L. (2011) The Importance of Measuring Psychosocial Functioning in Schizophrenia. Annals of General Psychiatry, 10, 18. http://dx.doi.org/10.1186/1744-859X-10-18

[24] Burns, J. (2009) Dispelling a Myth: Developing World Poverty, Inequality, Violence and Social Fragmentation Are Not Good for Outcome in Schizophrenia. African Journal of Psychiatry, 12, 200-205. http://dx.doi.org/10.4314/ajpsy.v12i3.48494

[25] Myers, N.L. (2011) Update: Schizophrenia across Cultures. Current Psychiatry Reports, 13, 305-311. http://dx.doi.org/10.1007/s11920-011-0208-0

[26] Aloba, O., Fatoye, O., Mapayi, B. and Akinsulore, S. (2013) A Review of Quality of Life Studies in Nigerian Patients with Psychiatric Disorders. African Journal of Psychiatry, 16, 333-337. http://dx.doi.org/10.4314/ajpsy.v16i5.44

[27] Asmal, L., Mall, S., Kritzinger, J., Chiliza, B., Emsley, R. and Swartz, L. (2011) Family Therapy for Schizophrenia: Cultural Challenges and Implementation Barriers in the South African Context. African Journal of Psychiatry, 14, 367-371. http://dx.doi.org/10.4314/ajpsy.v14i5.3

[28] Cantor-Graae, E. (2007) The Contribution of Social Factors to the Development of Schizophrenia: A Review of Recent Findings. Canadian Journal of Psychiatry, 52, 277-286.

[29] Bhui, K. and Tsangarides, N. (2008) Culture and Schizophrenia. Psychiatry, 7, 454-457. http://dx.doi.org/10.1016/j.mppsy.2008.08.005

[30] Kalra, G., Bhugra, D. and Shah, N. (2012) Cultural Aspects of Schizophrenia. International Review of Psychiatry, 24, 441-449. http://dx.doi.org/10.3109/09540261.2012.708649

[31] Lamb, H.R.L. and Weinberger, L.E. (2005) The Shift of Psychiatric Inpatient Care from Hospitals to Jails and Prisons. Journal of the American Academy of Psychiatry and the Law, 33, 529-534.

[32] Falkhoury, W. and Priebe, S. (2007) Deinstitutionalization and Reinstitutionalization: Major Changes in the Provision of Mental Healthcare. Psychiatry, 6, 313-316. http://dx.doi.org/10.1016/j.mppsy.2007.05.008

[33] Llorca, P.M., Miadi-Fargier, H., Lançon, C., Jasso Mosqueda, G., Casadebaig, F., et al. (2005) Cost-Effectiveness Analysis of Schizophrenic Patient Care Settings: Impact of an Atypical Antipsychotic under Long-Acting Injection Formulation. Encephale, 31, 235-246. http://dx.doi.org/10.1016/S0013-7006(05)82390-5

[34] Verdoux, H. (2007) The Current State of Adult Mental Health Care in France. European Archives of Psychiatry and Clinical Neurosciences, 257, 64-70. http://dx.doi.org/10.1007/s00406-006-0693-z

[35] Fraser, W.S. (2002) The Patient’s Journey: Mapping, Analysing and Improving Healthcare Processes. Kingsham Press, Chichester. 
[36] Strauss, A. and Corbin, J. (1998) Basics of Qualitative Research: Techniques and Procedures for Developing Grounded Theory. Sage, London.

[37] WintherJørgensen, M. and Phillips, L. (1999) Diskursanalyse som teori og metode (Discourse Analysis as a Theory and Method). Roskilde University Press, Roskilde.

[38] Kvale, S. (1996) An Introduction to Qualitative Research Interviewing. Sage Publications, Thousand Oaks.

[39] Trujols, J., Portella, M.J., Iraurgi, I., Campins, M.J., Siñol, N. and Pérez de losCobos, J. (2013) Patient-Reported Outcome Measures: Are They Patient Generated, Patient-Centred or Patient-Valued? Journal of Mental Health, 22, 555-562. http://dx.doi.org/10.3109/09638237.2012.734653

[40] Becker, T. and Kilian, R. (2008) Daily Living: Does This Matter for People with Mental Illness? International Review of Psychiatry, 20, 492-497. http://dx.doi.org/10.1080/09540260802564417

[41] Malterud, K. (2011) Kvalitative metoder i medisinsk forskning: en innføring. Universitetsforlaget. University of Copenhagen, Copenhagen.

[42] Karow, A. and Pajonk, F.G. (2006) Insight and Quality of Life in Schizophrenia: Recent Findings and Treatment Implications. Current Opinion in Psychiatry, 19, 637-641. http://dx.doi.org/10.1097/01.yco.0000245754.21621.c9

[43] Tseng, W.S. (2001) Handbook of Cultural Psychiatry. Academic Press, San Diego.

[44] Lin, K.M. and Kleinman, A.M. (1988) Psychopathology and Clinical Course of Schizophrenia: A Cross-Cultural Perspective. Schizophrenia Bulletin, 14, 555-567. http://dx.doi.org/10.1093/schbul/14.4.555

\section{List of Abbreviations}

PWS: Persons with Schizophrenia

QoL: Quality of Life

SZ: Schizophrenia

CBT: Cognitive Behavioural Training

UK: United Kingdom

US: United States (of America)

CMT: Centres Médicale Psychiatriques

HCP: Health Care Professionals

ICC: International Chamber of Commerce

ESOMAR: European Society for Opinion and Market Research

EphMRA. European Pharmaceutical Market Research Association

SHARE: Self-Help and Recovery Exchange (USA)

GLM: Gitte Lee Mortensen 